\title{
PERFORMANCE OF TRANSMISSION LOSS ON HYBRID MUFFLER BY USING ROCK WOOL AND GLASS FIBER AS A ABSORBING MATERIALS
}

\author{
Amit Kumar Gupta ${ }^{1}$ and Dr. Ashesh Tiwari ${ }^{2}$ \\ Mechanical Engineering Department, IET-Devi Ahilya University, Indore, INDIA
}

\begin{abstract}
Muffler is categorized in two broad manners as absorptive muffler and reactive muffler. A Muffler (silencer) is an important noise control element for reduction of machinery exhaust noise, fan noise, and other noise sources involving the flow of gases. Reactive mufflers which reduce noise by reflecting sound energy back to its source, and absorption mufflers, which absorb sound due to the energy dissipated in the sound-absorbing material. The attenuation levels of these types of muffler are dependent on the frequency of the noise source. Investigations on absorption mufflers have indicated that these have fairly good noise attenuation over a relatively wide frequency band. The combination of both reactive and absorptive muffler is termed as hybrid muffler. Hybrid muffler design may be expected to provide broadband high noise attenuation and low pressure drop. Experimental Two load setup and Wave 1-D is used to predict the transmission loss of hybrid muffler. Hybrid muffler generally includes the number of perforated tubes, number of perforated baffles with absorptive materials like asbestos, rock wool, bensoil, powertex \& advantex etc. Transmission loss measurement using hybrid muffler is discussed in this paper. Various sound absorption materials that are currently used for noise reduction are used. This paper shows the acoustic performance of packed dissipative muffler with the variation in packing density of absorptive material. Here easy available absorptive materials glass fiber \& rock wool is used with same space. This study is performed by taking four designs to observe the transmission loss performance by applying different absorptive materials with different packing density.
\end{abstract}

\section{KEYWORDS}

Transmission Loss (TL), Hybrid Muffler, Sound Absorptive Materials, Two Load Method, Wave 1-D.

\section{INTRODUCTION}

In the this study, a multi-chamber muffler with selective sound-absorbing material like, glass fiber and rock wool is considered to predict the transmission loss (TL). Zero mean flow measurements of these properties were carried out for mufflers ranging from simple expansion chambers to complex geometry using two load experimental method. Accurate determination and control of noise from automobiles is of significant importance in automotive exhaust system design and development [1]. Noise can be defined as unwanted sound. Muffler noise for an automobile is characterized by numerous parameters like insertion loss (IL), transmission loss (TL). Among the transmission loss and insertion loss, TL is most widely used in acoustical practice [2]. One more benefit of transmission loss measurement is that it is independent from source of noise. Generally white noise predicts the good result to evaluate transmission loss performance. The wave 1-D CFD tool is beneficial to save cost of computer resources and substantial amount of time [3]. The numerical methods are allowing the analysis of all types of acoustic mufflers. Here the experimental validation is important before to measure the transmission loss analysis with wave 1-D. So it is essential to validate the result with simplified model those transmission loss measurement is available with analytical and numerical result. The

DOI : 10.14810/ijamse.2015.4406 
one-dimensional analytical approach based on software Ricardo Wave 1-D is used to predict the acoustic attenuation characteristics of the multi-chamber muffler [4]. Mehdizadeh Et Al. (2005) performed his work in packed muffler. He used experimental as well the 3-D finite element analysis tool to measure the transmission loss of a muffler with desired frequency range. A hybrid muffler which is the combination of passive and reactive form of muffler was implemented and transmission loss is measured by using FEA tool. Then validation of result done by compared with the results obtained through numerical methods to maximal in transmission loss [5]. F.D. Denia, A. Selamet, F.J. Fuenmayor and R. Kirby (2007) proposed their work by taking absorbent resistivity, extended inlet and outlet ducts and the different porosity of the perforations. Fibrous and porous materials are used and found that increase in radius and chamber length gives maximum transmission loss [6]. Transmission loss (TL) is only a property of these four pole parameters and independent of the source and the termination impedances. For achieving higher transmission loss (TL), the expansion ratio must be correspondingly higher. However, higher expansion ratio introduces an upper frequency limit up to which the plane behavior is valid [7]. Zheng Et Al. proposed coupled hybrid model to the muffler's and result obtained by 4-pole parameters with 3-D FEM techniques. Mostly 4-pole parameters take the state variables like pressure and mass particle velocity shows at the inlet and outlet of the muffler [8]. Xu Et Al used the 2-D analytical approach to examined the effect of various thickness layer of fiber, expansion chamber diameter and material properties of fiber for the acoustic performance of dissipative silencers. For this purpose an analytical approach was proposed which based on the solution of Eigen equations for a circular dissipative expansion chamber. In this work the acoustic pressure and particle velocity throughout the muffler discontinuities were matched by imposing the continuities of the velocity and pressure which is integrated over discrete zones at the expansion or contraction [9]. To show the effects of flow-resistivity of noise absorbing material, porosity of perforation in baffle and pipe. Also geometrical parameters on the acoustic attenuation performance of the multi-chamber hybrid muffler were investigated in detail. In this paper the performance of various absorptive materials with Wave 1-D simulation and validation with cases of reactive mufflers by using TMM and FEA.

\section{EXPERIMENTAL FindingS OF TRANSMISSION LOSS FOR CENTRAL INLET AND Side OUTLET MUfFLER}

Sound analyzer have of two assemblies one is shown for input signal represent with green colour which refers to upstream and another for output signal represent red colour which refers to downstream with computer interfacing. The differences of FFT of these upstream and downstream signals are analyzed in Matlab based sound spectrum software which is developed by authors A. K. Gupta and Dr. A. Tiwari. The difference of upstream and downstream sound pressure level is calculated as transmission loss.

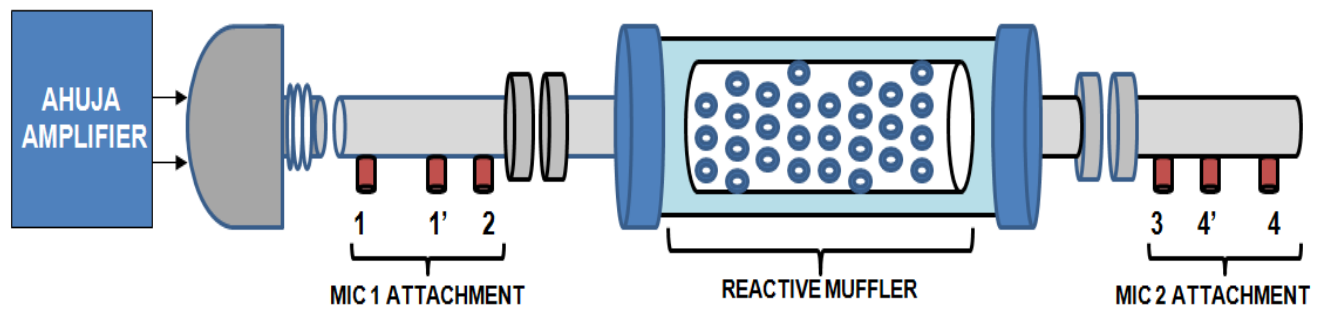

Figure 1. Schematic Layout of Test Rig 
This experiment is performed for reliable frequency range from 1 to $3000 \mathrm{~Hz}$. The measurement are taken in two slots with two locations 1-1' and another 4-4' it is shown in Figure 1. The measuring locations 1-2-3-4 are used to measure sound pressure for frequency range $10-400 \mathrm{~Hz}$, while the locations 1'-2-3-4' are used to measure sound pressure level in frequency range of 400$3000 \mathrm{~Hz}$ [4]. All other joining locations of test muffler are sealed except locations of microphone cap to avoid sound leakage shown in Figure 2. This circuit comprises of microphone for taking audio input inbuilt with mike interfacing assembly. This setup provides the selection of sensitivity, low-noise mike preamplifier circuit with variable gain of adjustment, different bandwidth adjustment and audible frequency range selection from $20 \mathrm{~Hz}$ to $20 \mathrm{KHz}$ in three bands selection. An NE5534 op-amp is introduced for the mike preamplifier stage because of its low input noise.

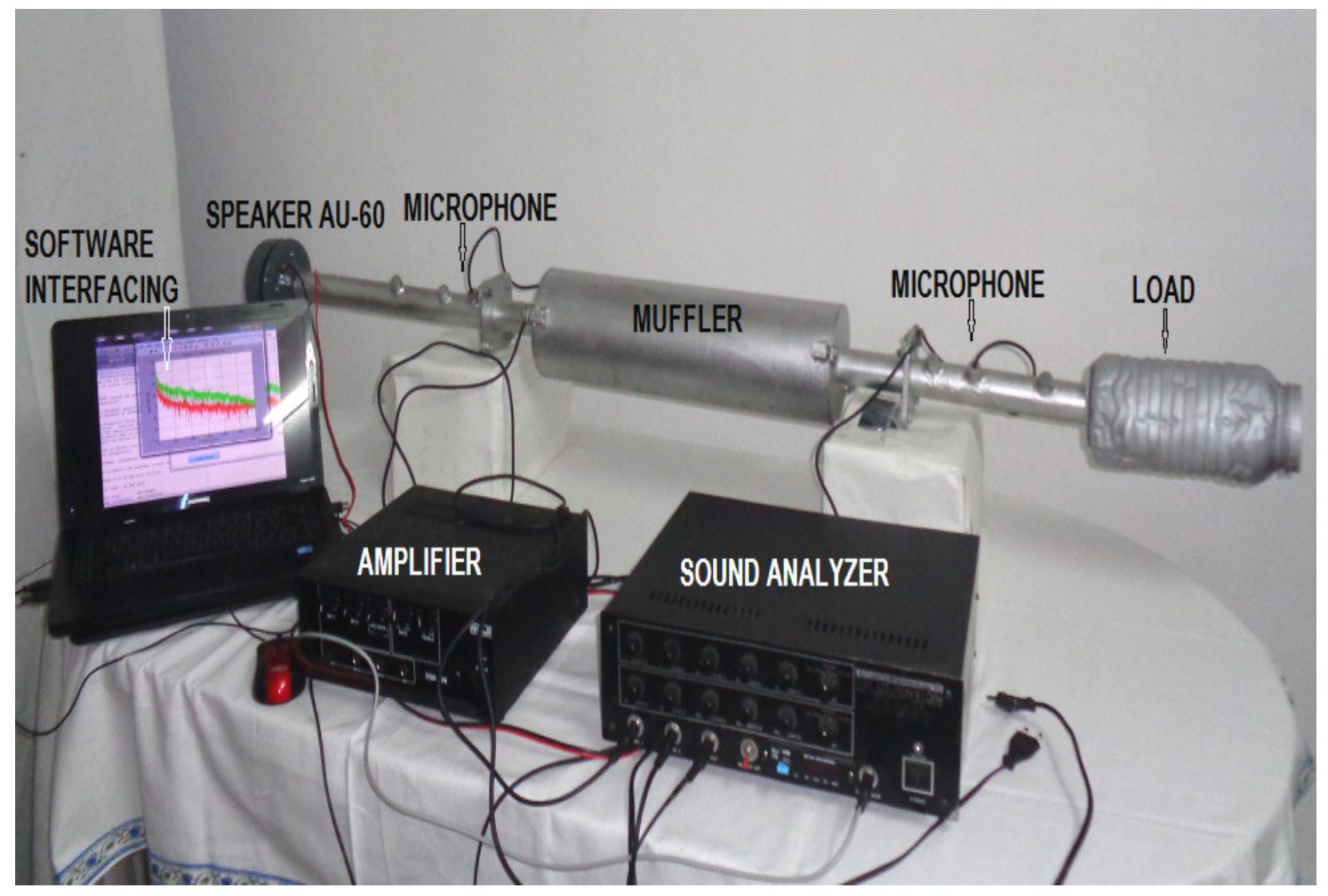

Figure 2. Experimental test set up based on two load method

\section{WAVE-1D RESULT VALIDATION}

WAVE 1-D is one dimensional computational fluid dynamics tool. It provides the 3-D simulation with 1-D approach to simulate engine as well exhaust acoustic performance. 1-D tools using transmission loss evaluation is accurately to predict all muffler configurations, shown the GUI Figure 3. This enables to acousticians to consider air system and combustion effects during analysis. One-dimensional tool is simplified for the acousticians because it saves the computational time and resources. Since wave 1-D is an engine specific package, it is very likely to be applied in an acoustical simulation application for different configuration of exhaust systems so it can clearly represent of the transmission loss performance [4].

The working fluid was perfect air having following boundary conditions:

1. Gas Volume approximately: $6636500 \mathrm{~mm}^{3}$.

2. Exhaust gas Temperature: $300 \mathrm{~K}$. 
3. Exhaust Gas pressure: 1.0 bar.

4. Initial fluid composition: Fresh Air.

5. Upper frequency Limit: $3000 \mathrm{~Hz}$.

6. Lower Frequency Limit: $50 \mathrm{~Hz}$.

Model is prepared on wave build 3D with inlet \& outlet boundary condition
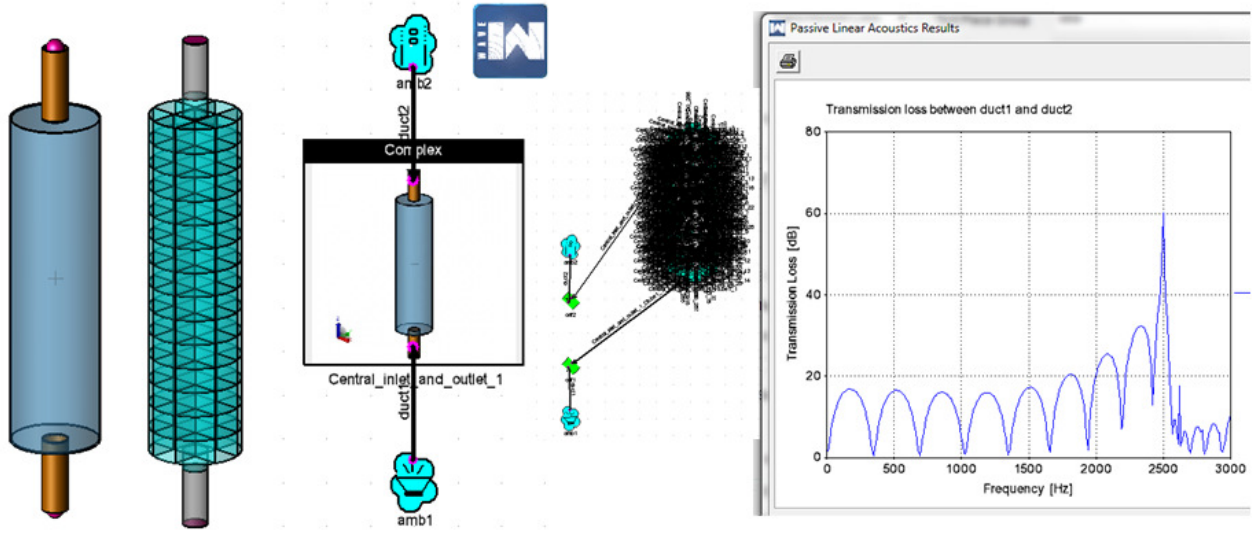

Figure 3. GUI of Wave 1-D for Central Inlet and Central outlet

\section{TL MEASUREMENT OF HYBRID MUfFLER}

An absorptive material can greatly increase the transmission loss of an exhaust system in the mid to high frequency ranges. But it is unable to improve the transmission loss in low frequency zone. As an absorption material is placed inside the muffler the effective expansion area reduces and this sound absorption material absorbs the pressure waves and reflects very little. Some of the absorption materials are glass fibers, asbestos, rock wool, advantex, bensoil, power tex etc [10].

\subsection{Absorptive Material Properties}

\begin{tabular}{|l|l|l|l|}
\hline Materials & Fiber density & Mean fiber diameter & Flow resistivity[Rayls/m] \\
\hline Glass Fibre & $2620 \mathrm{~kg} / \mathrm{m}^{3}$ & 24 microns & 4500 Rayls $/ \mathrm{m}$ \\
\hline Rock wool & $2840 \mathrm{~kg} / \mathrm{m}^{3}$ & 9.3 microns & 13813 Rayls $/ \mathrm{m}$ \\
\hline
\end{tabular}

Ignoring non-linearity (i.e. coefficients $\mathrm{c}$ and $\mathrm{d}=0$ ), the coefficients can be determined by solving the following equation at two points [11]:

$R_{0}=\frac{\eta}{\left(R_{m}\right)^{2}} * a(\mu)^{b}$

with the massivity, $\mu$, equal to (1-porosity) and defined by: $\mu=\frac{\rho_{\text {packing }}}{\rho_{\text {material }}}$

where: 
$\eta \quad=$ Dynamic viscosity of air

$\mathrm{R}_{\mathrm{m}} \quad=$ Mean average fiber radius

$\mathrm{a}, \mathrm{b} \quad=$ User-entered coefficients

$\rho_{\text {packing }}=$ Packing density of the material

$\rho_{\text {material }}=$ Packing density of the material

Solving these two equations for the two unknown coefficients gives:

$a=7.3$ and $b=1.627$

The WAVE absorptive material input data file for this case is:

! Absorptive material property data file for WAVE

! Advantex(C) Glass Fiber

! Source: Owens Corning (www.owenscorning.com)

2620.024 .0

COEFFS: 7.31 .6270 .750 .57

$298973 \quad \#$

10461381 \#
! Material density, Average diameter

! Material typelcoeffs a,b,c,d

! Temperatures for $\mathrm{Cp}$ definition

! Cp values for material

Resistivity is calculated using the following equation: Resistivity approximated as 51500 $\mathrm{Ns} / \mathrm{m}^{4} @ 0.05 \mathrm{~m} / \mathrm{s}$

$$
R=\frac{1}{U} \frac{\Delta P}{\Delta x}
$$

Where:

$\mathrm{U}=$ Velocity of sound

$\Delta x=$ Thickness of the fiber material

$\Delta P=$ Pressure drop across the fiber material

By using the resistivity values approximated at 0.05 metre/second, the linear coefficients of $\mathrm{a}$ and $\mathrm{b}$ can be easily calculated in the same way as that of the linear example. This gives:

$\mathrm{a}=5.7$ and $\mathrm{b}=1.7146$

Including the effects of non-linearity, the coefficients can be determined by solving the following equation at two points for each packing density:

$R=R_{0}+c\left(R_{0}\right)^{d}\left|U_{j}\right|$

Solving these two equations for the two unknown coefficients gives: $c=0.7$ and $\mathrm{d}=0.7$

The WAVE absorptive material input data file for this case is:

! Absorptive material property data file for WAVE

! Rock wool

2840.09 .3

COEFFS: $5.71 .71460 .7 \quad 0.7$

$296473 \#$

$8601080 \quad \#$

\footnotetext{
! Material density, Average diameter

! Material typelcoeffs a,b,c,d

! Temperatures for $\mathrm{Cp}$ definition

! Cp values for material
} 


\subsection{Experimental and Wave 1-D Result Comparison:}

Two materials have taken for the transmission loss performance Glass Fibre and Rock Wool respectively.

Four Design are considered for Hybrid Muffler

Design A: A single expansion chamber which consists of an external cylindrical duct and a perforated internal tube located co-axially. The two ends of the single expansion chamber are covered by circular flanges which are mounted on the internal tube. The dimension of expansion chamber is $500 \mathrm{~mm}$ long and $130 \mathrm{~mm}$ diameter and the internal tube has a diameter of $35 \mathrm{~mm}$ shown in Figure 4.

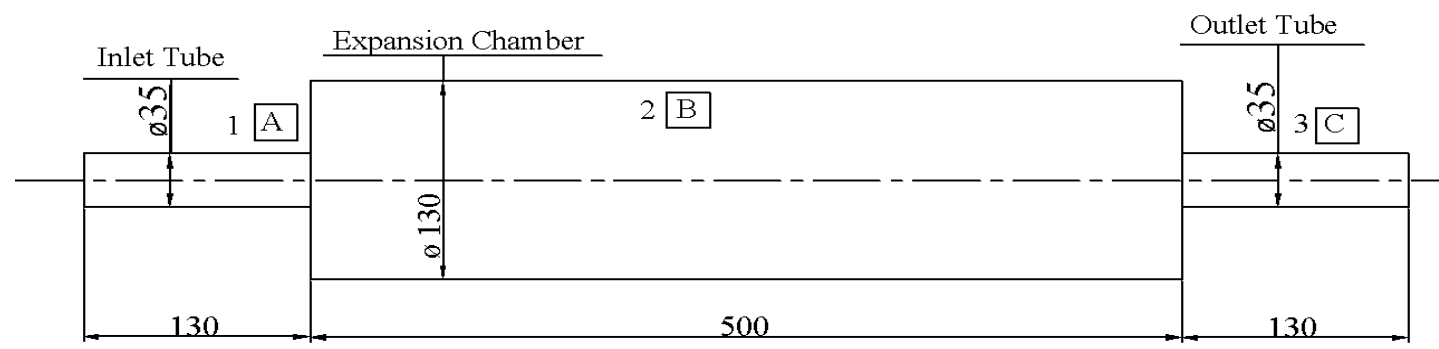

Figure 4. Central Inlet and Central outlet

Now it is filled with different packing density $60 \mathrm{~kg} / \mathrm{m}^{3}, 80 \mathrm{~kg} / \mathrm{m}^{3}$ and $100 \mathrm{~kg} / \mathrm{m}^{3}$ by using glass fiber and rock wool. Validation of experimental as well as wave 1-D results shows in Figure 5 which is comparable. So other design can also simulate wave 1-D. Figure 6 shows the packing with glass fiber and rock wool.
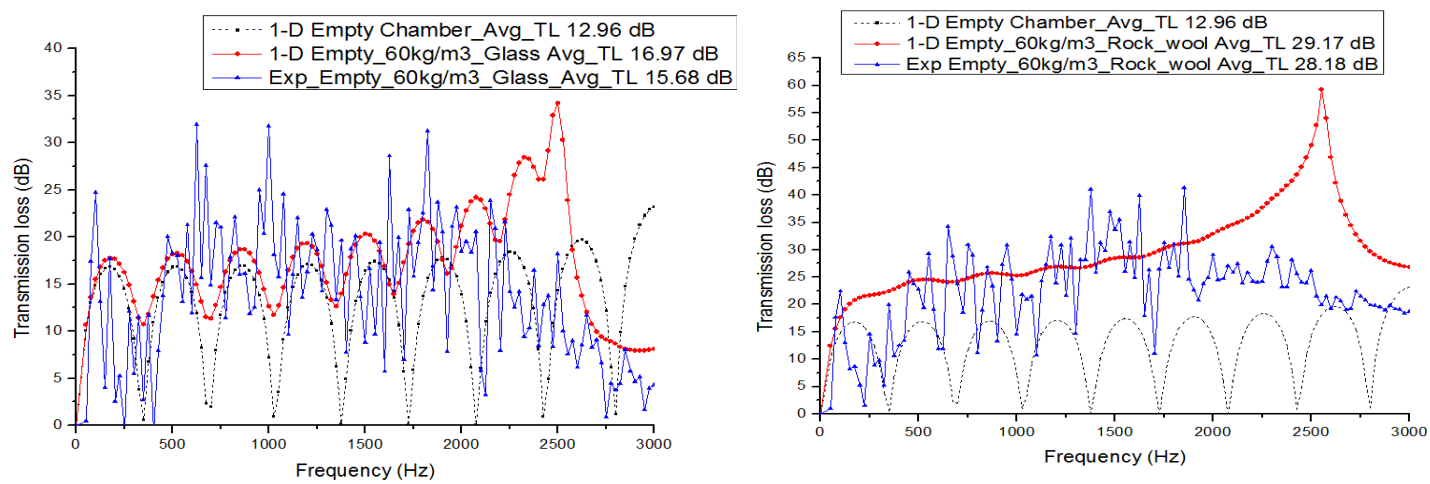

Figure 5. Result Comparison with packing density $60 \mathrm{~kg} / \mathrm{m}^{3}$ for Glass fibre and Rock wool
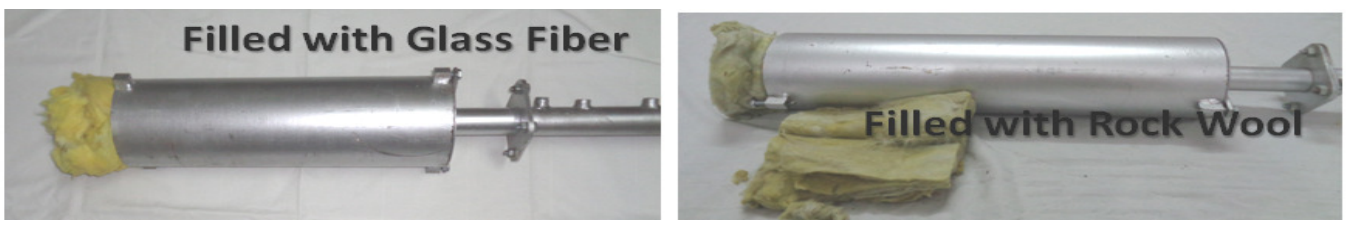

Figure 6. Empty chamber filled with different absorptive material Glass fibre and Rock wool 
Design B: Single expansion chamber with same dimension is used with concentric tube muffler having $22.75 \%$ porosity. Now it filled with different packing density have considered $60 \mathrm{~kg} / \mathrm{m}^{3}$, $80 \mathrm{~kg} / \mathrm{m}^{3}$ and $100 \mathrm{~kg} / \mathrm{m}^{3}$ by using glass fiber and rock wool, shown in Figure 7.

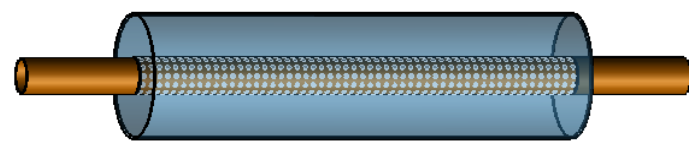

Figure 7. Central Inlet and Central outlet with perforated pipe

Design C: Single expansion chamber with same dimension is used with concentric tube muffler having $22.75 \%$ porosity and single baffle plate having porosity $19.66 \%$ located in mid position is used. Now it filled with different packing density have considered $60 \mathrm{~kg} / \mathrm{m}^{3}, 80 \mathrm{~kg} / \mathrm{m}^{3}$ and 100 $\mathrm{kg} / \mathrm{m}^{3}$ by using glass fiber and rock wool, shown in Figure 8 .

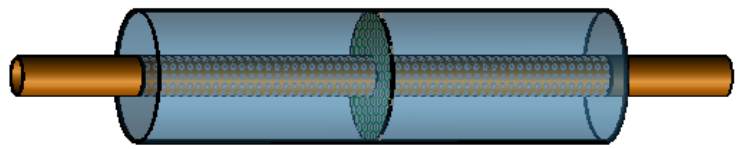

Figure 8. Central Inlet and Central outlet with perforated single baffle and pipe

Design D: Single expansion chamber with same dimension is used with concentric tube muffler having $22.75 \%$ porosity in the length of $332 \mathrm{~mm}$ and double baffle plate having $19.66 \%$ porosity. The distance between baffle is $332 \mathrm{~mm}$ at optimized position to achieve maximum transmission loss. Now it filled with different packing density have considered $60 \mathrm{~kg} / \mathrm{m}^{3}, 80$ $\mathrm{kg} / \mathrm{m}^{3}$ and $100 \mathrm{~kg} / \mathrm{m}^{3}$ by using glass fiber and rock wool, Figure 10, shows different packing.

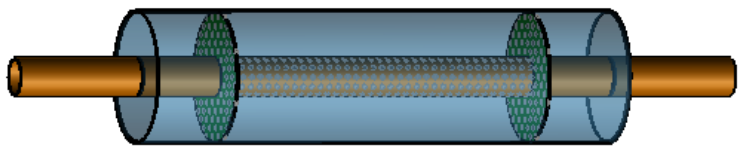

Figure 9. Central Inlet and outlet with perforated double baffle and pipe wave model

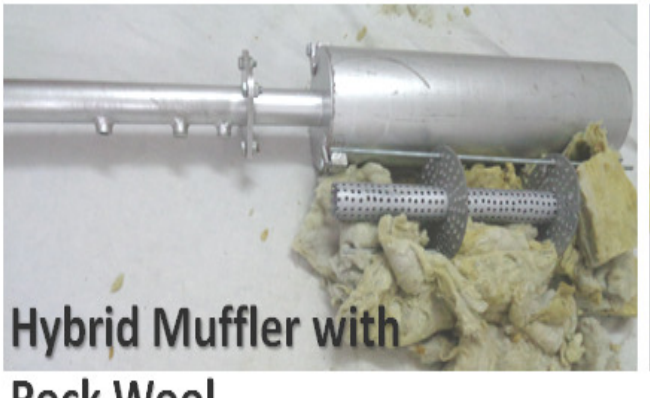

Rock Wool

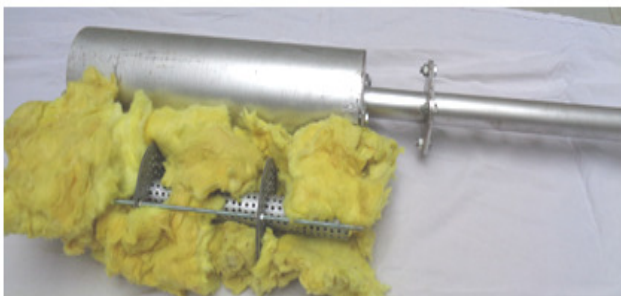

Hybrid Muffler with Glass Fiber

Figure 10. Central Inlet and outlet with perforated double baffle and pipe experimental model 


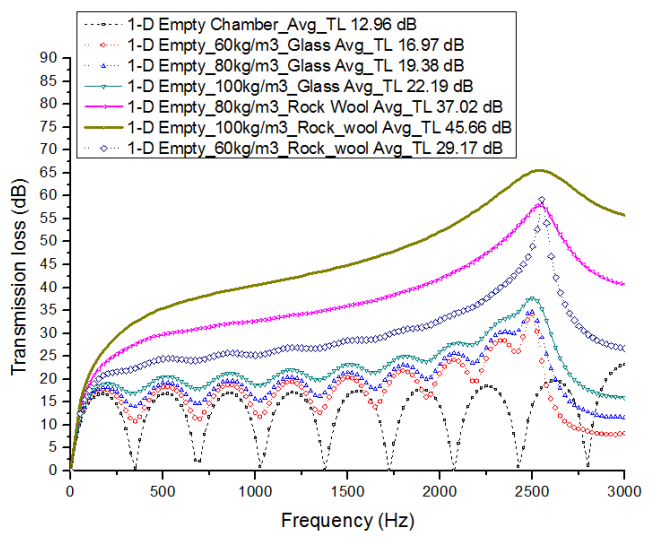

Figure 11. Design A result

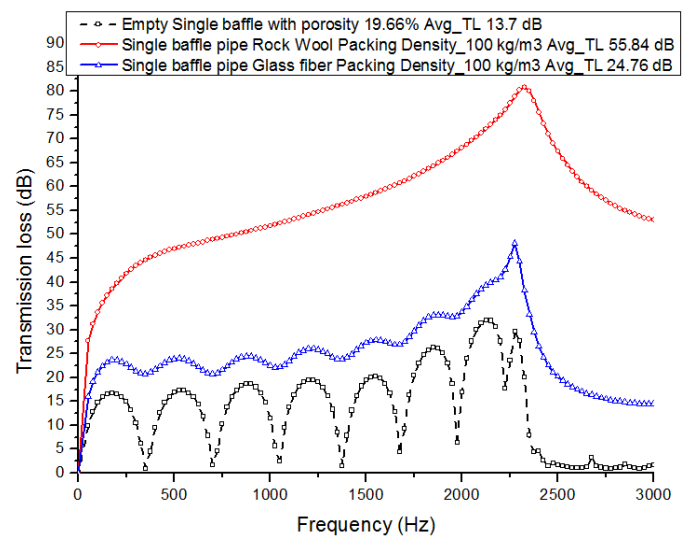

Figure13. Design C result

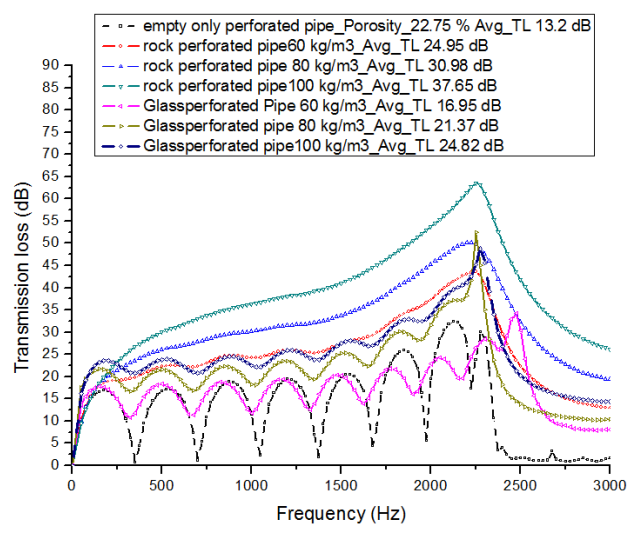

Figure 12. Design B result

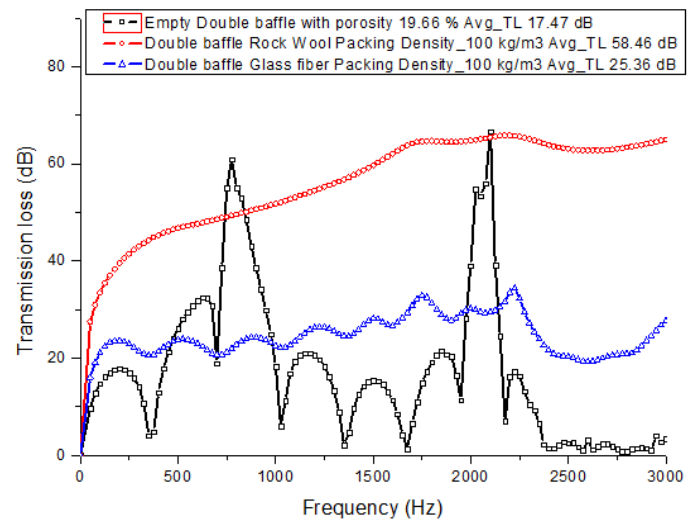

Figure 14. Design D result

\section{Conclusions}

An experimental method and wave 1-D simulation for transmission loss (TL) measurement in central inlet and central outlet muffler with packing density of glass fiber and rock wool shown in figure 5 with packing density $60 \mathrm{~kg} / \mathrm{m}^{3}$ shows the validation of result. With the comparison of rock wool and glass fiber as absorptive material shows that maximum transmission loss can be achieved with rock wool with respect to all packing density. Also it has investigated that hybrid muffler is beneficial to improve transmission loss performance in medium to high frequency zone. Attenuation curves represent in Figure 11, 12, 13 and 14 under four design observations i.e. empty expansion chamber, expansion chamber with perforated pipe, expansion chamber with single baffle and perforated pipe, expansion chamber with double baffle and perforated pipe. In design A the noise attenuation increased up $9.23 \mathrm{~dB}$ and $32.7 \mathrm{db}$ by using glass fiber and rock wool respectively. In other design also noise attenuation can be increased by using glass fiber and rock wool. Also it reveals that transmission loss performance can increased up to limited packing density. Finally design D of expansion chamber with optimized position of double baffle (perforation 19.66\%) and perforated pipe (perforation 22.75\%) is more suitable to achieve high transmission loss. The proposed work has done with glass fiber and rock wool to evaluate the transmission loss performance of the muffler. Similar configurations can also be compared with different absorptive material like asbestos, advantex \& power tex etc. Further modification in central inlet and central outlet muffler by keeping same space constraint and adding a variable perforation in baffle and protruding tube can improve the muffler performance. 


\section{ACKNOWLEDGEMENTS}

Thanks to support from everyone including parents, my guide Dr. Ashesh Tiwari, all family members and friends. Especially I would like to give my acknowledgement of gratitude towards the IET-DAVV, Indore (MP), India to provide me research facility.

\section{REFERENCES}

[1] Yeh L.J., "Computer-aided optimal design of a single-chamber muffler with side inlet/outlet under space constraints”, Applied Acoustics Vol. 32 pp 96-106, 1995.

[2] Nakra B. C., Said W. K. \& Nassir A., "Investigations on mufflers for internal Combustion engines.”, Applied Acoustics Vol. 14 pp 135-145, 1981.

[3] Mohamed R. et. al., "Modelling and analysis of single expansion chamber using response surface methodology" international journal of mechanical and materials engineering vol.2 issue 1, 2012.

[4] Gupta A.K., Tiwari A., "Modeling For Transmission Loss Prediction Of Different Shapes Of Acoustic Muffler With An Experimental Analysis", Journal Of Experimental \& Applied Mechanics, Vol 6, No 1, 2015.

[5] Mehdizadeh O. Z., Paraschivoiu, M., , A threedimensional finite element approach for predicting the transmission loss in mufflers and silencers with no mean flow", Applied Acoustics, 66, 902-918, 2005.

[6] Kirby R. Et. al., Analytic mode matching for a circular dissipative silencer containing mean low and a perforated pipe, Journal of the Acoustical Society of America, 122, 3471-3482, 2007.

[9] Kirby R., , A comparison between analytic and numerical methods for modeling automotive issipative silencers with mean flow, Journal of Sound and Vibration,325,565-582, 2009.

[7] Ji Z., Su S., Liu C., Acoustic Attenuation Performance Analysis of Three pass Perforated Tube Muffler with End-resonator, SAE International, 01-0894, 2008.

[8] Zheng S. et.al., Acoustic Matching Simulation of Muffler with Hybrid Approach, SAE International, 01-1516, 2011.

[9] Selamet A. et.al., Sound attenuation in dissipative expansion chambers, Journal of Sound and Vibration, 272, 1125-1133, 2004.

[10] Tyler W. Et.al. ,Muffler characterization with implementation of the finite element method and experimental techniques, Michigan Technological University, 2011.

[11] J. Eberspaecher GmbH \& Co.

\section{Authors}

Mr. Amit Kumar Gupta currently He is pursuing Ph.D. in the area of Muffler Noise Reduction. Presently he is working as Assistant Professor in Mechanical Engineering Department, IET-DAVV, Indore, India. His areas of interest are finite element analysis tool and acoustics. E-mail address: $\underline{\text { akgupta@ietdavv.edu.in. }}$

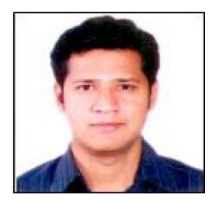

Dr. Ashesh Tiwari is working as Professor \& Head of the Mechanical Engineering Department, IET-DAVV, Indore (MP), India. He has published more the 50 research papers and guided 6 Ph.D. E-mail address: atiwari@ ietdavv.edu.in.

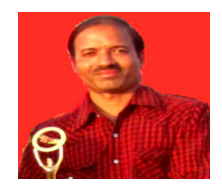

